Scientific paper

\title{
Synthesis, Crystal Structure, and Catalytic Property of Dioxomolybdenum(VI) Complex Derived from 4-Bromo-N'-(4-diethylamino-2-hydroxybenzylidene) benzohydrazide
}

\author{
Li Wang, Yong-Jun Han, Qing-Bin Li and Ling-Wei Xue* \\ College of Chemistry and Chemical Engineering, Pingdingshan University, Pingdingshan Henan 467000, P.R. China \\ *Corresponding author: E-mail: pdsuchemistry@163.com
}

Received: 25-06-2016

\begin{abstract}
A novel dioxomolybdenum(VI) complex, $\left[\mathrm{MoO}_{2} \mathrm{~L}(\mathrm{MeOH})\right]$, where $\mathrm{L}$ is the anion of 4-bromo- $N$ '-(4-diethylamino-2hydroxybenzylidene)benzohydrazide, has been synthesized and characterized by physico-chemical methods and single crystal X-ray determination. In the complex the Mo atom is in octahedral coordination, with three donor atoms of the hydrazone ligand, two oxo groups, and one methanol $\mathrm{O}$ atom. The complex exhibits catalytic property for the sulfoxidation reactions. In the presence of the complex a 93\% conversion of the sulfide to the corresponding sulfoxide was observed within $60 \mathrm{~min}$ and the $100 \%$ conversion was achieved after $2 \mathrm{~h}$.
\end{abstract}

Keywords: Dioxomolybdenum; Hydrazone; Crystal structure; Catalytic property; Sulfoxidation

\section{Introduction}

Molybdenum complexes with multi-dentate ligands have received remarkable attention in recent years for their catalytic properties ${ }^{1}$ and molecular structures. ${ }^{2}$ Catalytic oxo transfer properties especially epoxidation and sulfoxidation by dioxomolybdenum complexes are industrially important. Many types of ligands with various functional groups have been synthesized to prepare molybdenum complexes with the aim to explore new and efficient catalytic materials. ${ }^{3}$ Salicylaldehyde and its derivatives have been widely used as ligands for the preparation of metal complexes with various applications. ${ }^{4} \mathrm{~A}$ large number of molybdenum complexes with Schiff base ligands have been reported. ${ }^{5}$ Some of the dioxomolybdenum complexes have shown oxygen atom transfer properties as they were found to oxidize thiols, hydrazine, polyketones, and tertiary phosphines. ${ }^{6}$ Recently, we reported the catalytic property of a dioxomolybdenum(VI) complex. ${ }^{7}$ As a continuation of such work, we report in this paper the synthesis, structure, and catalytic property of a new dioxomolybdenum(VI) complex, $\left[\mathrm{MoO}_{2} \mathrm{~L}(\mathrm{MeOH})\right]$, where $\mathrm{L}$ is the anion of 4-bromo- $N$ '-(4-dimethylamino-2-hydroxybenzylidene)benzohydrazide (Scheme 1).<smiles>CCN(CC)c1ccc(/C=N/NC(=O)c2ccc(Br)cc2)c(O)c1</smiles>

Scheme 1. The hydrazone $\mathrm{H}_{2} \mathrm{~L}$.

\section{Experimental}

\section{1. Materials and Methods}

4-Diethylaminosalicylaldehyde, 4-bromobenzohydrazide and $\mathrm{MoO}_{2}(\mathrm{acac})_{2}$ were purchased from Fluka. Other reagents and solvents were analytical grade and used without further purification. The hydrazone was prepared according to the literature method. ${ }^{8}$ Elemental $(\mathrm{C}, \mathrm{H}$, and $\mathrm{N}$ ) analyses were made on a Perkin-Elmer Model 240B automatic analyzer. IR spectra were recorded on an IR-408 Shimadzu 568 spectrophotometer. ${ }^{1} \mathrm{H}$ NMR data was recorded on a Bruker $300 \mathrm{MHz}$ spectrometer. 


\section{2. Synthesis of $\left[\mathrm{MoO}_{2} \mathrm{~L}(\mathrm{MeOH})\right]$}

$\mathrm{MoO}_{2}(\mathrm{acac})_{2}(0.1 \mathrm{mmol}, 33.5 \mathrm{mg})$ was dissolved with methanol $(10 \mathrm{~mL})$, to which was added with stirring a methanolic solution $(10 \mathrm{~mL})$ of $\mathrm{H}_{2} \mathrm{~L}(0.1 \mathrm{mmol}, 39.0$ $\mathrm{mg}$ ). The mixture was stirred at reflux for $30 \mathrm{~min}$ to give a yellow solution. The solution was slowly evaporated in air to give yellow block-shaped single crystals, which were collected by filtration and dried in evacuated desiccator containing anhydrous $\mathrm{CaCl}_{2}$. The yield is $41 \mathrm{mg}(75 \%)$. Elemental analysis found: $\mathrm{C}, 41.8 ; \mathrm{H}, 4.1 ; \mathrm{N}, 7.5 \%$, $\mathrm{C}_{19} \mathrm{H}_{22} \mathrm{BrMoN}_{3} \mathrm{O}_{5}$ calcd: $\mathrm{C}, 41.6 ; \mathrm{H}, 4.0 ; \mathrm{N}, 7.7 \%$.

\section{3. X-ray Diffraction}

Crystal data of the complex were collected with a Bruker Apex II diffractometer using Mo $\mathrm{K}_{\alpha}$ radiation $(0.71073 \AA)$. The data were processed with SAINT $^{9}$ and corrected for absorption using SADABS. ${ }^{10}$ Multi-scan absorption corrections were applied with $\psi$ scans. ${ }^{11}$ Structure of the complex was solved by direct method using SHELXS-97 and refined by full-matrix least-squares

Table 1. Crystal and structure refinement data for the complex

\begin{tabular}{ll}
\hline Molecular formula & $\mathbf{C}_{\mathbf{1 9}} \mathbf{H}_{\mathbf{2 2}} \mathbf{B r M o N}_{\mathbf{3}} \mathbf{O}_{\mathbf{5}}$ \\
\hline Molecular weight & 548.2 \\
Crystal system & Monoclinic \\
Space group & $P 2_{1} / c$ \\
$a / \AA$ & $13.9971(8)$ \\
$b / \AA$ & $7.4182(4)$ \\
$c / \AA$ & $21.409(1)$ \\
$\beta / /^{\circ}$ & $107.319(1)$ \\
$V / \AA^{3}$ & $2122.2(2)$ \\
$Z$ & 4 \\
$D_{\text {calc }}\left(\mathrm{g} \mathrm{cm}^{-3}\right)$ & 1.716 \\
$\mu\left(\mathrm{mm}^{-1}\right)$ & 2.536 \\
Reflections measured & 19023 \\
Unique reflections & $3927\left[R_{\text {int }}=0.0301\right]$ \\
Observed reflections $(I>2 \sigma(I))$ & 3241 \\
Parameters & 268 \\
Restraints & 1 \\
${\text { Goodness of fit on } F^{2}}_{R_{1}, w R_{2}[I \geq 2 \sigma(I)]^{\mathrm{a}}}^{R_{1}, w R_{2}(\text { all data })^{\mathrm{a}}}$ & 1.027 \\
\hline
\end{tabular}

${ }^{\mathrm{a}} R_{1}=\sum|| F_{o}|-| F_{c} \| / \Sigma\left|F_{o}\right|, w R_{2}=\left[\sum w\left(F_{o}^{2}-F_{c}^{2}\right)^{2} / \sum w\left(F_{o}^{2}\right)^{2}\right]^{1 / 2}$
Table 2. Selected bond lengths $(\AA)$ and angles $\left({ }^{\circ}\right)$ for the complex

\begin{tabular}{lclc}
\hline Bond lengths & & & \\
\hline Mo1-O1 & $1.927(2)$ & Mo1-O2 & $2.0096(19)$ \\
Mo1-O3 & $1.686(2)$ & Mo1-O4 & $2.384(2)$ \\
Mo1-N1 & $2.228(2)$ & Mo1-O5 & $1.697(2)$ \\
\hline Bond angles & & & \\
\hline O1-Mo1-O2 & $149.61(9)$ & O1-Mo1-N1 & $81.59(8)$ \\
O5-Mo1-O1 & $102.56(9)$ & O1-Mo1-O4 & $82.21(9)$ \\
O3-Mo1-O1 & $99.68(10)$ & O3-Mo1-O2 & $97.01(10)$ \\
O3-Mo1-O5 & $105.92(12)$ & O3-Mo1-N1 & $96.89(10)$ \\
O5-Mo1-N1 & $155.60(10)$ & O5-Mo1-O2 & $96.98(9)$ \\
O2-Mo1-N1 & $71.29(8)$ & O3-Mo1-O4 & $171.34(10)$ \\
O5-Mo1-O4 & $81.75(9)$ & N1-Mo1-O4 & $74.95(8)$ \\
O2-Mo1-O4 & $77.79(8)$ & & \\
\hline
\end{tabular}

techniques on $F^{2}$ using anisotropic displacement parameters. ${ }^{12}$ All of the non-hydrogen atoms of the complex were refined anisotropically. The $\mathrm{H}$ atom of the methanol ligand were located from electronic density maps and refined isotropically. The other hydrogen atoms were located as riding model. Crystallographic data for the complex are summarized in Table 1. Selected bond lengths and angles are listed in Table 2.

\section{4. Catalytic Oxidation}

The dioxomolybdenum(VI) complex $(0.001 \mathrm{M})$ and phenyl methyl sulfide $(0.100 \mathrm{M})$ were dissolved in the mixture of $\mathrm{CH}_{2} \mathrm{Cl}_{2}$ and $\mathrm{CH}_{3} \mathrm{OH}$ (6:4) with 1,3,5-trimethoxybenzene $(0.100 \mathrm{M})$ as the internal standard. The solution was cooled to 283(2) K, to which was added dropwise $\mathrm{H}_{2} \mathrm{O}_{2}(35 \% \mathrm{w} / \mathrm{w}, 0.125 \mathrm{M})$. An aliquot of the solution $(2.0 \mathrm{~mL})$ was quenched with $\mathrm{Na}_{2} \mathrm{SO}_{3}(0.100 \mathrm{M}, 5 \mathrm{~mL})$, then extracted for three times with $\mathrm{CH}_{2} \mathrm{Cl}_{2}(4 \mathrm{~mL})$. The solvent of the organic phase was removed, and the residue was dissolved in $\mathrm{CDCl}_{3}(0.6 \mathrm{~mL})$ and analyzed by ${ }^{1} \mathrm{H}$ NMR to determine the yield.

\section{Results and Discussion}

The complex was prepared by the reaction of the hydrazone ligand with $\mathrm{MoO}_{2}(\mathrm{acac})_{2}$ in a 1:1 molar ratio (Scheme 2). The crystals of the complex are soluble in<smiles>CCN(CC)c1ccc(/C=N/NC(=O)c2ccc(Br)cc2)c(O)c1</smiles>

Scheme 2. The preparation of the complex. 
DMSO, DMF, MeOH, EtOH and MeCN. Well-shaped single crystals of the complex can be obtained from $\mathrm{MeOH}$.

\section{1. Crystal Structure Description of the Dioxomolybdenum Complex}

The molecular structure of the dioxomolybdenum complex is shown in Figure 1. In the complex the Mo atom is coordinated by the phenolic oxygen, imino nitrogen, enolic oxygen of the hydrazone ligand, two oxo oxygen and one methanol oxygen, forming an octahedral coordination. The hydrazone ligand coordinates to the $\mathrm{MoO}_{2}$ moiety by forming a five- and a six-membered chelate rings. The methanol molecule is weakly coordinated to the Mo atom, as indicated by the long bond value. The equatorial plane defined by atoms $\mathrm{O} 1, \mathrm{O} 2, \mathrm{~N} 1$ and $\mathrm{O} 5$ show a high degree of planarity, with mean deviation from the plane of 0.038(3) $\AA$. The Mo1 atom deviates from the least-squares equatorial plane by $0.346(1) \AA$ in the direction of the axial atom $\mathrm{O} 3$. The coordinate bond lengths are comparable to those observed in similar complexes. ${ }^{13}$ The distortion of the octahedral coordination is indicated by the bond angles, ranging from $71.29(8)$ to $105.92(12)^{\circ}$ for the cis angles and from 149.61(9) to $171.34(10)^{\circ}$ for the trans angles. The dihedral angle between the two benzene rings of the hydrazone ligand is $0.3(5)^{\circ}$.

In the crystal structure of the complex, the complex molecules are linked through intermolecular hydrogen bonds of types $\mathrm{O} 4-\mathrm{H} 4 \cdots \mathrm{N} 2^{\mathrm{i}}[\mathrm{O} 4-\mathrm{H} 4=0.85(1) \AA$, $\mathrm{H} 4 \cdots \mathrm{N} 2^{\mathrm{i}}=2.01(2) \AA, \mathrm{O} 4 \cdots \mathrm{N} 2=2.834(3) \AA, \mathrm{O} 4-\mathrm{H} 4 \cdots \mathrm{N} 2^{\mathrm{i}}$ $=164(4)^{\circ}$; symmetry code for i: $\left.-x, 1-y,-z\right]$, to form dimers (Figure 2).

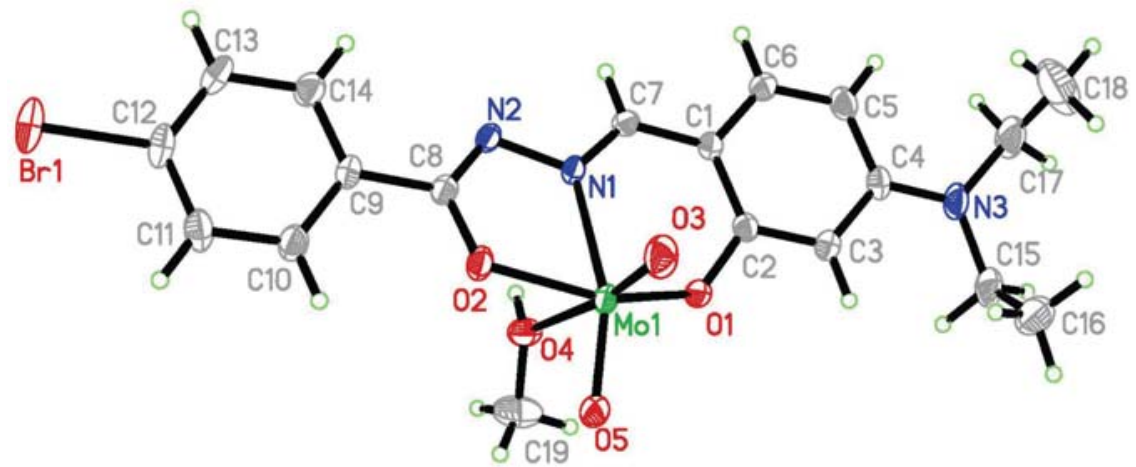

Figure 1. Molecular structure of the complex at $30 \%$ probability displacement.

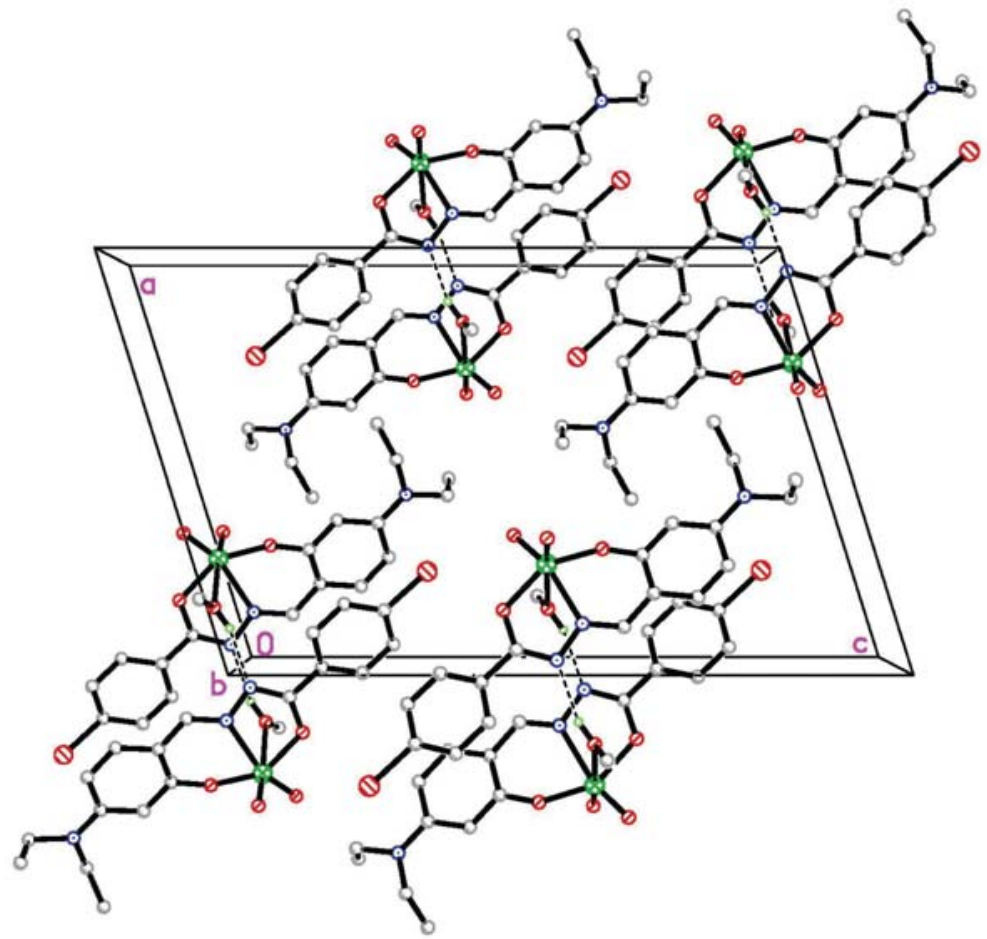

Figure 2. The hydrogen bonds linked dimeric structure of the complex. 


\section{2. Infrared and Electronic Spectra}

In the IR spectrum of the hydrazone compound ( $\mathrm{Fi}$ gure S1) the stretching bands attributed to $\mathrm{C}=\mathrm{O}, \mathrm{C}=\mathrm{N}$, $\mathrm{C}-\mathrm{OH}$ and $\mathrm{NH}$ at $1634,1603,1130$ and $3183 \mathrm{~cm}^{-1}$ are present, respectively. In the IR spectrum of the dioxomolybdenum complex (Figure S2) two prominent bands at 948 and $850 \mathrm{~cm}^{-1}$ are present, which can be attributed to the $\mathrm{MoO}_{2}$ group. ${ }^{14}$ The bands due to $v_{\mathrm{C}=\mathrm{O}}$ and $v_{\mathrm{NH}}$ are absent in the dioxomolybdenum complex. This suggests occurrence of keto-imino tautomerization of the hydrazone ligand during coordination to the Mo atom. The typical $\mathrm{C}=\mathrm{N}$ absorption of the dioxomolybdenum complex is observed at $1595 \mathrm{~cm}^{-1} .{ }^{15}$ The weak bands in low wave numbers can be attributed to the Mo-O and Mo-N vibrations.

The electronic spectrum of the dioxomolybdenum complex recorded in $\mathrm{MeCN}$ display strong and medium absorption bands in the region 370-420 and 260-300 nm (Figure S3). These peaks are assigned as charge transfer transitions of the type $\mathrm{N}(p \pi)-\mathrm{Mo}(d \pi)$ LMCT and $\mathrm{O}(p \pi)-\mathrm{Mo}(d \pi) \mathrm{LMCT}^{16}{ }^{16}$ as the ligand based orbitals are either $\mathrm{N}$ or $\mathrm{O}$ donor types. The slight change of $\lambda_{\max }$ values within each set of peaks may be due to the difference of electron donating capacity of the hydrazone ligand.

\section{3. Catalytic Sulfoxidation}

The catalytic oxidation test of the dioxomolybdenum complex as catalyst on the oxidation of sulfide under homogeneous conditions using methyl phenyl sulfide as the substrate is shown as Scheme 3. Hydrogen peroxide was used as oxidant in 1.25 equivalent based on the sulfide substrate. Reactions were run with $1 \mathrm{~mol} \%$ of catalyst based on the substrate at $10{ }^{\circ} \mathrm{C}$. NMR technique was used to monitor the formation of the sulfoxides with 1,3,5-trimethoxybenzene (TMB) as internal standard. The reaction was started by the addition of $\mathrm{H}_{2} \mathrm{O}_{2}$. A control reaction under the same condition without the complex present leads to less than $1 \%$ sulfide conversion within $4 \mathrm{~h}$. In the presence of the dioxomolybdenum complex a $93 \%$ conversion of the sulfide to the corresponding sulfoxide was observed within 60 min and the $100 \%$ conversion was achieved after $2 \mathrm{~h}$.

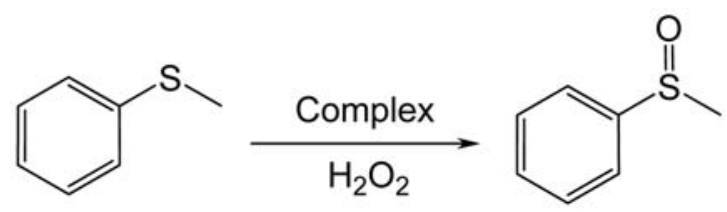

Scheme 3. The sulfoxidation process.

\section{Supplementary Mateiral}

CCDC-1487659 contain the crystallographic data for the complex. The data can be obtained at http://www.ccdc.cam.ac.uk/const/retrieving.html or from the Cambridge Crystallographic Data Centre (CCDC), 12 Union Road, Cambridge CB2 1EZ, UK; fax: +44(0)1223336033 or e-mail: deposit@ ccdc.cam.ac.uk.

\section{Acknowledgments}

This research was supported by the National Sciences Foundation of China (No. 20676057 and 20877036) and Top-class foundation of Pingdingshan University (No. 2008010).

\section{References}

1. (a) C. A. Gamelas, A. C. Gomes, S. M. Bruno, F. A. A. Paz, A. A. Valente, M. Pillinger, C. C. Romao, I. S. Goncalves, Dalton Trans. 2012, 41, 3474-3484; http://dx.doi.org/10.1039/c2dt11751g

(b) L. S. Feng, J. S. Maass, R. L. Luck, Inorg. Chim. Acta 2011, 373, 85-92;

http://dx.doi.org/10.1016/j.ica.2011.03.060

(c) M. Bagherzadeh, M. Amini, A. Ellern, L. K. Woo, Inorg. Chem. Commun. 2012, 15, 52-55;

http://dx.doi.org/10.1016/j.inoche.2011.09.037

(d) S. Rayati, N. Rafiee, A. Wojtczak, Inorg. Chim. Acta 2012, 386, 27-35.

http://dx.doi.org/10.1016/j.ica.2012.02.005

2. (a) B. I. Ceylan, Y. D. Kurt, B. Ulkuseven, J. Coord. Chem. 2009, 62, 757-766; http://dx.doi.org/10.1080/00958970802339669

(b) M. N. Sokolov, M. A. Mikhailov, P. A. Abramov, V. P. Fedin, J. Struct. Chem. 2012, 53, 197-201; http://dx.doi.org/10.1134/S0022476612010283

(c) S.-P. Gao, J. Coord. Chem. 2011, 64, 2869-2877.

http://dx.doi.org/10.1080/00958972.2011.608163

3. (a) M. Ghorbanloo, R. Bikas, G. Malecki, Inorg. Chim. Acta 2016, 445, 8-16;

http://dx.doi.org/10.1016/j.ica.2016.02.018

(b) Z. Moradi-Shoeili, M. Zare, M. Bagherzadeh, S. Ozkar, S. Akbayrak, J. Coord. Chem. 2016, 69, 668-677; http://dx.doi.org/10.1080/00958972.2015.1137290

(c) R. G. Mohamed, F. M. Elantabli, N. H. Helal, S. M. ElMedani, Synth. React. Inorg. Met.-Org. Nano-Met. Chem. 2015, 45, 1839-1850;

(d) M. R. Maurya, N. Saini, F. Avecilla, Inorg. Chim. Acta 2015, 438, 168-178; http://dx.doi.org/10.1016/j.ica.2015.09.013

(e) E. Kinoshita, K. Arashiba, S. Kuriyama, A. Eizawa, K. Nakajima, Y. Nishibayashi, Eur. J. Inorg. Chem. 2015, 10, 1789-1794. http://dx.doi.org/10.1002/ejic.201500017

4. (a) S. Mandal, R. Saha, B. Mahanti, M. Fleck, D. Bandyopadhyay, Inorg. Chim. Acta 2012, 387, 1-7; http://dx.doi.org/10.1016/j.ica.2011.12.035

(b) M. A. Vazquez-Fernandez, M. I. Fernandez-Garcia, A. 
M. Gonzalez-Noya, M. Maneiro, M. R. Bermejo, M. J. Rodriguez-Douton, Polyhedron 2012, 31, 379-385;

http://dx.doi.org/10.1016/j.poly.2011.09.031

(c) F. Habib, P.-H. Lin, J. Long, I. Korobkov, W. Wernsdorfer, M. Murugesu, J. Am. Chem. Soc. 2011, 133, 8830-8833; http://dx.doi.org/10.1021/ja2017009

(d) K.-H. Yang, Acta Chim. Slov. 2014, 61, 629-636;

(e) S.-S. Qian, X. Zhao, J. Wang, Z. You, Acta Chim. Slov. 2015, 62, 828-833. http://dx.doi.org/10.1016/j.ica.2012.02.005

5. (a) S. Rayati, N. Rafiee, A. Wojtczak, Inorg. Chim. Acta 2012, 386, 27-35;

(b) N. K. Ngan, K. M. Lo, C. S. R. Wong, Polyhedron 2012 , 33, 235-251;

http://dx.doi.org/10.1016/j.poly.2011.11.057

(c) S. Duman, I. Kizilcikli, A. Koca, M. Akkurt, B. Ulkuseven, Polyhedron 2010, 29, 2924-2932;

http://dx.doi.org/10.1016/j.poly.2010.07.022

(d) R. D. Chakravarthy, K. Suresh, V. Ramkumar, D. Chand, Inorg. Chim. Acta 2011, 376, 57-63;

http://dx.doi.org/10.1016/j.ica.2011.05.033

(e) C. P. Rao, A. Sreedhara, P. V. Rao, M. B. Verghese, K. Rissanen, E. Kolehmainen, N. K. Lokanath, M. A. Sridhar, J. S. Prasad, J. Chem. Soc. Dalton Trans. 1998, 2383-2393. http://dx.doi.org/10.1039/a801226a

6. (a) M. Mancka, W. Plass, Inorg. Chem. Commun. 2007, 10, 677-680; http://dx.doi.org/10.1016/j.inoche.2007.02.029

(b) S. N. Rao, N. Kathale, N. N. Rao, K. N. Munshi, Inorg. Chim. Acta 2007, 360, 4010-4016;

http://dx.doi.org/10.1016/j.ica.2007.05.035

(c) R. Dinda, S. Ghosh, L. R. Falvello, M. Tomas, T. C. S. Mak, Polyhedron 2006, 25, 2375-2382.

http://dx.doi.org/10.1016/j.poly.2006.02.002

7. X.-M. Hu, L.-W. Xue, C.-X. Zhang, G.-Q. Zhao, Synth. React.
Inorg. Met.-Org. Nano-Met. Chem. 2014, 44, 713- 718.

8. (a) L. Shi, Z.-P. Xiao, Z. Zhuang, Z.-Z. Zhong, H.-L. Zhu, Acta Crystallogr. 2007, E63, o4726;

(b) L.-W. Xue, Y.-J. Han, G.-Q. Zhao, Y.-X. Feng, J. Chem. Crystallogr. 2011, 41, 1599-1603.

http://dx.doi.org/10.1007/s10870-011-0146-z

9. Bruker, SMART and SAINT. Area Detector Control and Integration Software; Bruker Analytical X-ray Instruments Inc.: Madison, WI, USA, 1997.

10. G. M. Sheldrick, SADABS. Program for Empirical Absorption Correction of Area Detector Data; University of Göttingen: Göttingen, Germany, 1997.

11. A. C. T. North, D. C. Phillips, F. S. Mathews, Acta Crystallogr., 1968, A24, 351-359. http://dx.doi.org/10.1107/S0567739468000707

12. G. M. Sheldrick, SHELXL-97. Program for the Refinement of Crystal Structures; University of Göttingen: Göttingen, Germany, 1997.

13. (a) S. N. Rao, K. N. Munshi, N. N. Rao, M. M. Bhadbhade, E. Suresh, Polyhedron 1999, 18, 2491-2497; http://dx.doi.org/10.1016/S0277-5387(99)00139-4 (b) W.-X. Xu, W.-H. Li, Synth. React. Inorg. Met.-Org. Nano-Met. Chem. 2012, 42, 160-164.

14. T. Głowiak, L. Jerzykiewicz, J. M. Sobczak, J. J. Ziółkowski, Inorg. Chim. Acta 2003, 356, 387-392. http://dx.doi.org/10.1016/S0020-1693(03)00301-3

15. G. Romanowski, M. Wera, Polyhedron 2010, 29, 27472754. http://dx.doi.org/10.1016/j.poly.2010.06.030

16. (a) N. R. Pramanik, S. Ghosh, T. K. Raychaudhuri, S. S. Mandal, J. Coord. Chem. 2009, 62, 3845-3582; http://dx.doi.org/10.1080/00958970903176887 (b) M. L. H. Nair, D. Thankamani, Russ. J. Coord. Chem. 2010, 36, 259-268. http://dx.doi.org/10.1134/S1070328410040044

\section{Povzetek}

Sintetizirali smo nov dioksomolibdenov(VI) kompleks, [ $\left.\mathrm{MoO}_{2} \mathrm{~L}(\mathrm{MeOH})\right]$, kjer je L anion 4-bromo- $N$ '-(4-dietilamino2-hidroksibenziliden)benzohidrazida, in ga okarakterizirali s fizikalno-kemijskimi metodami in monokristalno rentgensko analizo. V kompleksu je Mo atom oktaedrično koordiniran s tremi donorskimi atomi hidrazonskega liganda, dvema okso skupinama in atomom kisika z molekule metanola. Kompleks ima katalitične lastnosti za reakcijo sulfoksidacije. Ob prisotnosti kompleksa pride v času 60 min do $93 \%$ pretvorbe sulfida do ustreznega sulfoksida ter do 100\% pretvorbe po $2 \mathrm{~h}$. 